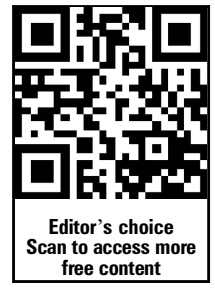

Handling editor Tore $\mathrm{K}$ Kvien

- Additional material is published online only. To view please visit the journal online (http://dx.doi.org/10.1136/ annrheumdis-2014-205459).

${ }^{1}$ Division of Rheumatology, Immunology \& Allergy, Brigham \& Women's Hospital and Harvard Medical School, Boston, Massachusetts, USA

${ }^{2}$ Department of Epidemiology, Harvard School of Public Health, Boston, Massachusetts, USA

\section{Correspondence to} Dr Bing Lu, Division of Rheumatology, Immunology \& Allergy, Brigham \& Women's Hospital and Harvard Medical School, 75 Francis Street PBBB3, Boston, MA 02115, USA; blu1@partners.org

Bing Lu and Linda T Hiraki are co-lead authors.

Received 22 February 2014 Revised 12 June 2014 Accepted 11 July 2014 Published Online First 23 July 2014

\section{CrossMark}

\section{Sinked}

- http://dx.doi.org/10.1136/ annrheumdis-2014-205741

To cite: Lu B, Hiraki LT, Sparks JA, et al. Ann Rheum Dis 2014;73:1914-1922.

\title{
Being overweight or obese and risk of developing rheumatoid arthritis among women: a prospective cohort study
}

\author{
Bing Lu, ${ }^{1}$ Linda T Hiraki, ${ }^{1,2}$ Jeffrey A Sparks, ${ }^{1}$ Susan Malspeis, ${ }^{1}$ Chia-Yen Chen, ${ }^{1,2}$ \\ J Adebukola Awosogba, ${ }^{1}$ Elizabeth V Arkema, ${ }^{2}$ Karen H Costenbader, ${ }^{1}$ \\ Elizabeth W Karlson ${ }^{1}$
}

\section{ABSTRACT}

Objectives To examine the relationship between being overweight or obese and developing rheumatoid arthritis (RA) in two large prospective cohorts, the Nurses' Health Study (NHS) and Nurses' Health Study II (NHSII).

Methods We followed 109896 women enrolled in NHS and 108727 in NHSII who provided lifestyle, environmental exposure and anthropometric information through biennial questionnaires. We assessed the association between time-varying and cumulative Body Mass Index (BMI) in WHO categories of normal, overweight and obese $\left(18.5-<25,25.0-<30, \geq 30.0 \mathrm{~kg} / \mathrm{m}^{2}\right)$ and incident RA meeting the 1987 American College of Rheumatology (ACR) criteria. We estimated HRs for overall RA and serologic subtypes with Cox regression models adjusted for potential confounders. We repeated analyses restricted to RA diagnosed at age 55 years or younger.

Results During 2765195 person-years of follow-up (1976-2008) in NHS and 1934518 person-years (1989-2009) in NHSII, we validated 1181 incident cases of RA (826 in NHS, 355 in NHSII). There was a trend toward increased risk of all RA among overweight and obese women (HR $(95 \% \mathrm{Cl}) 1.37$ (0.95 to 1.98) and 1.37 (0.91, 2.09), $p$ for trend=0.068). Among RA cases diagnosed at age 55 years or younger, this association appeared stronger (HR 1.45 (1.03 to 2.03) for overweight and 1.65 (1.34 to 2.05) for obese women ( $p$ trend $<0.001)$ ). Ten cumulative years of being obese, conferred a $37 \%$ increased risk of RA at younger ages (HR 1.37 (1.11 to 1.69)).

Conclusions Risks of seropositive and seronegative RA were elevated among overweight and obese women, particularly among women diagnosed with RA at earlier ages.

\section{INTRODUCTION}

Obesity remains a major health issue affecting as many as two-thirds of adults in the USA and one-third children. ${ }^{1}$ There is increased morbidity and mortality attributable to obesity: overweight or obese individuals are at increased risk of hypertension, dyslipidemia, type 2 diabetes, coronary heart disease, stroke, some cancers (including endometrial, breast and colon), osteoarthritis, sleep apnoea and asthma. ${ }^{12}$ Alarmingly, obesity rates are quickly rising.

One pathway by which obesity may increase the risk of several diseases is via systemic inflammation.
Adipose tissue secretes proinflammatory adipocytederived cytokines, or adipokines, into the circulation. ${ }^{3}$ Elevated levels of inflammatory adipokines further stimulate adipose tissue expansion, thus inducing a positive feedback cycle of adipokine secretion and tissue inflammation. ${ }^{4}$ Specifically, proinflammatory adipokines have been linked to the accumulation of adipose tissue deep in the thorax and around viscera. ${ }^{5} 6$ These visceral fat stores, in particular, are thought responsible for the generation of elevated markers of systemic inflammation. ${ }^{7}$ A large cohort study observed that obese participants' sera had 60\% higher C-reactive protein (CRP) levels, 28\% higher tumour necrosis factor (TNF)- $\alpha$ levels, 36\% higher amyloid A levels, $15 \%$ higher white blood cell counts and 46\% higher interleukin-6 (IL-6) levels, when compared to those of normal weight after adjusting for potential confounders including sex and age.

Rheumatoid arthritis (RA) is a systemic autoimmune disease of unknown aetiology that leads to systemic inflammation and synovial joint destruction. Prior studies examining the association between Body Mass Index (BMI) and the development of RA have yielded differing results. Several studies have observed an association between obesity and increased odds of RA, ${ }^{8-12}$ in particular, anticitrullinated protein antibody (ACPA)-negative RA. ${ }^{13}$ Conversely, other case-control studies, ${ }^{14} 15$ and cross-sectional and prospective cohort studies, ${ }^{11} 16$ have observed no association between obesity and RA, or serologic subtypes of RA. A single study reported an association between obesity and the development among ACPA-negative $\mathrm{RA}$ in women and an inverse association between BMI and ACPA-positive RA in men. ${ }^{17}$ These conflicting results may reflect modification of the association between BMI and RA by age of RA diagnosis. Potentially, RA onset at older ages may be due to different risk factors than RA diagnosed at younger ages. We aimed to investigate the association between increased BMI at different stages of adulthood and risk of developing RA among women enrolled in the prospective Nurses' Health Study (NHS) cohorts.

\section{METHODS}

\section{Population for analysis}

The NHS was established in 1976, and enrolled 121701 US female registered nurses, aged 30- 
55 years, recruited through the state licensing boards. Nurses' Health Study II (NHSII) is a prospective cohort study that began in 1989, enrolling 116430 female nurses aged 2542 years. Women in both cohorts complete detailed, mailed questionnaires every 2 years regarding their health outcomes and lifestyle practices. Based on self-report, more than $90 \%$ of women in both cohorts are Caucasian, reflecting the ethnicity of women entering the nursing profession during the recruitment years. Follow-up rate has been high with about $5.0 \%$ of persontime lost to follow-up. In both cohorts, women completed an initial questionnaire and have been followed biennially to update exposures, lifestyle, health practices and disease diagnoses. The National Death Index is searched every 2 years for nonresponders, to validate mortality. ${ }^{18}$ All participants provided informed consent. All aspects of this study were approved by the Partners Healthcare Institutional Review Board.

\section{RA case identification}

RA case identification was a two-stage procedure. The connective tissue disease (CTD) screening questionnaire (CSQ) was mailed to participants who self-reported a new physician diagnosis of RA. ${ }^{19}$ Medical records of those with positive CSQ were then requested and reviewed independently by two boardcertified rheumatologists to validate RA according to the 1987 American College of Rheumatology RA classification criteria. ${ }^{20}$ Participants who self-reported any CTD, including RA, prior to baseline were excluded. Women included in these analyses had new, definite, confirmed incident RA, documented serologic status (rheumatoid factor, RF and/or ACPA) and date of diagnosis and symptom onset from the medical records. For women diagnosed with RA prior to ACPA (CCP tests) availability in the USA in the 1990s, serostatus was determined solely by rheumatoid factor. RF was available in nearly all women, but if not tested, serologic status was coded negative.

We included participants in NHS and NHSII cohorts who had body weight and height data at baseline (1976 in NHS and 1989 in NHSII). We excluded prevalent cases of RA diagnosed before 1976 in NHS and 1989 in NHSII. We censored all women who reported psoriasis, psoriatic arthritis or other CTDs at self-report date, unless the diagnosis was subsequently confirmed as RA. Women lost to follow-up were censored at their last response to questionnaires because incident RA could not subsequently be identified. We excluded women with underweight $\left(\mathrm{BMI}<18.5 \mathrm{~kg} / \mathrm{m}^{2}\right)$ since this may indicate other preclinical conditions.

\section{Definitions of overweight and obesity}

All information about body weight, height and study covariates was self-reported on the mailed questionnaires administered every 2 years since 1976 in NHS, and since 1989 in NHS II, and updated through follow-up. The questionnaire also asked about weight in early adulthood (age 18 years). The accuracy of self-reported anthropometric measures was evaluated among 140 NHS participants by having trained technicians visit those participants on two occasions. ${ }^{21}$ After adjustment for age and within-person variability, the Pearson correlation coefficient between self-report and the average of the two technician measurements was 0.97 for weight. ${ }^{21}$ BMI was calculated as weight in kilograms divided by the square of height in metres $\left(\mathrm{kg} / \mathrm{m}^{2}\right)$. The Pearson correlation coefficient between any two adjacent BMI measures was more than 0.94. The missing values of BMI were imputed using the method of Last Observation Carry Forward (LOCF) for one cycle. We used the WHO classification of BMI with the categories for normal weight $\left(18.5 \mathrm{~kg} / \mathrm{m}^{2}\right.$ $\leq$ BMI $\left.<25.0 \mathrm{~kg} / \mathrm{m}^{2}\right)$, overweight $\left(25.0 \mathrm{~kg} / \mathrm{m}^{2} \leq \mathrm{BMI}<30 \mathrm{~kg} / \mathrm{m}^{2}\right)$ and obese $\left(\mathrm{BMI} \geq 30.0 \mathrm{~kg} / \mathrm{m}^{2}\right)$ as time-varying exposures. For BMI at age 18 years, we considered the possibility that being at the higher range of normal BMI during adolescence may confer risk of RA as an adult and therefore used categories of 18.5$<20.0,20.0-<23.0,23.0-<25.0$, and $\geq 25.0 \mathrm{~kg} / \mathrm{m}^{2} .^{22}$

In order to investigate the potential cumulative dose-effect of obesity, we calculated average BMI values from all the preceding measures over the study period (cumulative average BMI). If BMI was missing for one questionnaire cycle, the measurements from the available years were averaged. As an alternative method to assess cumulative effects, we estimated the risk of RA associated with years of duration of obesity. ${ }^{23}$ This method assumes that persistent obesity has a biologic effect.

\section{Covariates}

We selected covariates based on prior studies associating them with either RA or BMI, and included each as time-varying variables. $^{24}{ }^{25}$ Cigarette smoking is a strong environmental risk factor for RA and is correlated with alcohol intake. ${ }^{24}$ We adjusted for pack-years of smoking (product of years of smoking and packs of cigarettes per day) in analyses. Previous studies found moderate alcohol intake may reduce the risk of RA. $^{26}{ }^{27}$ Alcohol consumption was assessed by a semiquantitative food frequency questionnaire. We categorised alcohol consumption as: $<5.0,5.0-15.0$ and $\geq 15 \mathrm{~g} /$ day. $^{28}$ Measures of physical activity were calculated from total metabolic equivalent (MET) scores determined by average oxygen consumption per unit time estimated for specific activities as compared to resting oxygen uptake. ${ }^{29}$ As a proxy of socioeconomic status, we included the 2000 US Census tract median income for the nurses' residences. Additional covariates were considered and included in sensitivity analyses. These included reproductive covariates of parity and duration of breastfeeding, age at menarche, oral contraceptive use, menopausal status and postmenopausal hormone use. $^{25}$ A prior study of self-reported periodontal surgery and tooth loss as proxies for history of periodontal disease and RA in NHS did not demonstrate a significant association, hence we did not include covariates for periodontal disease in our multivariable models. ${ }^{30}$

\section{Statistical analysis}

All analyses were conducted separately in NHS and NHSII and results were combined using random effects models. ${ }^{31}$ Descriptive statistics, such as frequency tables for categorical variables and minimum, maximum, mean and SD for continuous variables were used to summarise the data and detect outliers and missing values. Baseline age-adjusted characteristics across categories of BMI were compared using analysis of variance or Kruskal-Wallis tests for continuous variables, and $\chi^{2}$ tests for categorical variables.

For each woman, person-years of follow-up were calculated from the date of return of the baseline questionnaire to the end of follow-up defined as RA diagnosis, censorship due to reported psoriasis or rheumatic disease not confirmed as RA, censorship due to cancer, death, or end of follow-up, whichever came first. We used Cox proportional hazards $(\mathrm{PH})$ models to assess associations between time-varying or cumulative BMI categories of overweight and obesity on the incidence of RA after controlling for time-varying covariates including age, smoking, alcohol use, physical activity, as well as median census-tract household income. We also evaluated women's reproductive factors (menarche age, parity/breastfeeding, menopausal status and postmenopausal hormone use) in separate models. The 
multivariable-adjusted HRs approximating relative risk (RR) for associations between categories of BMI and RA were calculated along with their 95\% CIs. The population-attributable risk (PAR) was also calculated to evaluate the risk difference between overweight/obese women and normal weight women. Tests for linear trend were performed by using the median value of each BMI category and modelling these as continuous variables. The PH assumption was tested by including an interaction term between BMI and the follow-up time in the Cox proportional model. The $\mathrm{PH}$ assumption was valid in both cohorts ( $p$ for interaction was 0.72 in NHS, 0.81 in NHSII). Similarly we also did not find the $\mathrm{PH}$ assumption violation with other covariates in the model. Pooled HR estimates of the two cohorts were calculated using a random effects model, and heterogeneity was assessed using the DerSimonian-Laird method. ${ }^{31}$ All analyses were performed using SAS V.9.3 (SAS Institute, Cary, North Carolina, USA).

Analyses were repeated stratified by RA serologic status (RF and/or ACPA positive) in both cohorts to evaluate whether the association between BMI and RA differed by serological status of RA cases. To examine the difference in effects of overweight and obesity by age at RA diagnosis, we restricted analyses to those with earlier RA onset. Currently, there are no universal definitions for early and late onset RA, with age thresholds ranging from 45 years to 65 years in past studies. ${ }^{32}$ On average, women reach their peak BMI between the ages of 50 and $59 .{ }^{33}$ One past study observed that obesity was associated with onset of RA among women diagnosed on average at age 55.9 years. ${ }^{10}$ Therefore, we defined diagnosis at or before age 55 years as early onset of RA based on this prior literature and our hypothesis that risk factors for early onset RA differ from later onset RA. In NHS, $41 \%$ of the RA cases were early onset RA, while more than $83 \%$ were early onset RA in NHSII, reflecting younger ages at the start of NHSII and shorter follow-up than
NHS. Additionally, we assessed the interactions of BMI categories with age, smoking pack-years and alcohol consumption to evaluate the potential effect modifications.

We performed several sensitivity analyses. We added additional covariates for women's reproductive factors previously observed to be associated with RA in some studies (menarche age, parity/breastfeeding, menopausal status and post-menopausal hormone use) to the models. We performed lagged analyses updating BMI measures up to 4 years and 6 years prior to RA diagnosis to avoid potential reverse causation. We repeated analyses after excluding participants with a history of cancer at baseline and censoring incident cancer cases at self-reported date. Finally, to consider the measurement error of BMI due to pregnancy, we conducted a sensitivity analysis in NHSII where women were asked their pregnancy status. For women reporting a current pregnancy, we replaced current BMI with the measure of one cycle before (carry forward by one cycle).

\section{RESULTS}

Our study included a total of 109896 women in NHS and 108727 women in NHSII contributing 2765195 person-years of follow-up from 1976 to 2008 ( 32 years) in NHS and 1934518 person-years of follow-up from 1989 to 2009 (20 years) in NHSII. We validated 1181 incident cases of RA (826 in NHS, 355 in NHSII). Table 1 summarises the baseline characteristics of NHS and NHSII participants by BMI category. The prevalence of obesity was $8.3 \%$ in NHS and $11.8 \%$ in NHSII. NHS women, on average, were older at enrolment (mean age 42.9 (SD \pm 7.2 ) years) compared with NHSII women (mean age 34.4 (SD \pm 4.7 ) years). NHS RA cases were, on average, about 10 years older than NHSII RA cases at diagnosis of RA (age 57.9 vs age 47.6 ) with $41 \%$ of RA cases and $83 \%$ of NHSII RA cases diagnosed at or before 55 years of age. A higher

Table 1 Age-standardised baseline characteristics of Nurses' Health Study (NHS) (N=109 896) and Nurses' Health Study II (NHS II) participants ( $\mathrm{N}=108727$ ) by Body Mass Index (BMI) categories

\begin{tabular}{|c|c|c|c|c|c|c|}
\hline & \multicolumn{3}{|l|}{ NHS } & \multicolumn{3}{|l|}{ NHS II } \\
\hline & $18.5 \leq \mathrm{BMI}<25.0$ & $25.0 \leq \mathrm{BMI}<30.0$ & $\mathrm{BMI} \geq 30.0$ & $18.5 \leq \mathrm{BMI}<25.0$ & $25.0 \leq \mathrm{BMI}<30.0$ & $\mathrm{BMI} \geq 30.0$ \\
\hline Number of participants & $78215(71.2 \%)$ & $22515(20.5 \%)$ & $9166(8.3 \%)$ & $74944(68.9 \%)$ & $20970(19.3 \%)$ & $12813(11.8 \%)$ \\
\hline Age in years, mean (SD) & $43.0(7.2)$ & $43.1(7.1)$ & $43.1(7.1)$ & $34.2(4.7)$ & $34.7(4.5)$ & $35.0(4.4)$ \\
\hline $\begin{array}{l}\text { Census tract median family } \\
\text { income } \$(\times 1000) \text {, mean }(S D)^{*}\end{array}$ & $66.0(26.7)$ & $61.0(23.2)$ & $57.7(21.5)$ & $61.8(23.1)$ & $57.5(20.4)$ & $54.1(18.3)$ \\
\hline \multicolumn{7}{|l|}{ Pack-year smoking (packyr),\% } \\
\hline Never & 43.4 & 48.2 & 52.0 & 65.5 & 64.6 & 65.7 \\
\hline$<20$ & 33.4 & 30.1 & 29.3 & 29.6 & 29.0 & 27.1 \\
\hline $20+$ & 23.2 & 21.7 & 18.8 & 4.9 & 6.4 & 7.2 \\
\hline \multicolumn{7}{|l|}{ Alcohol use (g/day), \% } \\
\hline$<5.0$ & 61.4 & 73.3 & 84.1 & 77.3 & 83.5 & 89.4 \\
\hline $5.0-14.9$ & 24.8 & 18.1 & 11.1 & 19.4 & 13.9 & 8.7 \\
\hline $15.0+$ & 13.9 & 8.6 & 4.8 & 3.3 & 2.6 & 1.9 \\
\hline Physical activity (total METs), mean (SD) & $15.1(21.9)$ & $12.2(19.6)$ & $9.8(15.5)$ & $26.9(38.6)$ & $21.4(31.3)$ & $17.5(28.2)$ \\
\hline Menarche before age 12 years, \% & 20.6 & 28.4 & 35.8 & 20.9 & 30.8 & 38.8 \\
\hline Oral contraceptive use, \% & 48.5 & 43.8 & 42.7 & 84.2 & 83.2 & 80.3 \\
\hline Parous, \% & 91.7 & 91.8 & 91.0 & 69.4 & 73.5 & 68.1 \\
\hline Breastfeeding $\geq 12$ months $\%$ & 17.5 & 17.0 & 16.6 & 25.7 & 23.5 & 18.8 \\
\hline Postmenopausal (PM), \% & 31.4 & 32.1 & 31.8 & 2.1 & 2.6 & 3.7 \\
\hline Current hormone use in PM \% & 27.2 & 22.8 & 18.0 & 86.4 & 83.2 & 76.6 \\
\hline
\end{tabular}

*Median census tract family income was measured in 1986 for NHS and 1989 for NHSII. The values were based on the 2000 census data and adjusted by Consumer Price Index.

MET, metabolic equivalent. 
proportion of NHSII participants reported never smoking, higher levels of physical activity, and oral contraceptive use.

The age-adjusted incidence rate of RA was 30/100 000 person-years in NHS, ranging from 27 to 32/100 000 personyears, and 18/100 000 person-years in NHSII, ranging from 12 to $27 / 100000$ person-years, across increasing categories of BMI. These incidence rates are lower than that previously reported in Rochester, Minnesota, USA, yet consistent with prior reports from Massachusetts, USA, and other European countries. $^{34}$ In analyses of time-varying BMI, we observed a trend toward increased risk of RA among overweight and obese women (pooled HR (95\% CI) were 1.37 (0.95 to 1.98) and $1.37(0.91$ to 2.09$)$, $\mathrm{p}$ for trend $=0.068)$ ) compared to women of normal BMI, that was statistically significant in NHSII, but not in NHS (table 2). In analyses restricted to those women diagnosed with RA at age 55 years or younger (312 cases in NHS, 306 cases in NHSII), the association appeared stronger in both cohorts with the pooled HR of 1.45 (1.03 to 2.03) for overweight women and HR 1.65 (1.34 to 2.05) for obese women. The PAR \% for overweight and obesity was $10 \%$ in NHS and $40 \%$ in NHSII. When we repeated our analyses stratifying cases by RA serologic status, we observed comparable positive associations between overweight and obesity and seropositive and seronegative RA, and associations were also stronger for RA cases diagnosed at earlier ages (table 2). By contrast, when we restricted to RA cases whose diagnosis age was over 55 years, we did not observe a significant association between BMI and risk of RA (data not shown), though this was limited by small numbers of older onset RA cases in NHSII. There was no statistically significant difference in the association between BMI and RA among heavy smokers ( $\geq 10$ pack years) compared to light or non-smokers ( $<10$ pack years) ( $p$ for interaction was 0.550 in NHS, 0.486 in NHSII, see online supplementary table S1). Similarly, no significant interactions were observed between BMI and age or physical activity on risk of RA in both cohorts.

Analyses using cumulative average BMI demonstrated that being overweight or obese was significantly associated with increased risk of RA overall (pooled HR 1.23 (1.06 to 1.44) for obese women, 1.34 (1.06 to 1.68) for overweight women) (table 3 ). For RA cases diagnosed at age 55 years or younger, the pooled HR was $1.26(1.01,1.57)$ for overweight women and HR 1.51 (1.20 to 1.88) for obese women. Additionally, using an alternative way to measure the long-term effect of obesity, the number of years of obesity was also associated with risk of RA only among those diagnosed at age 55 years or younger. Ten cumulative years of being obese, conferred a $37 \%$ increased risk of RA onset $\leq$ age 55 years (HR 1.37, 95\% CI 1.11 to 1.69 ). When stratified by serologic status, this 10 -year obesity risk was significant among seropositive RA cases (HR 1.37 (1.10 to 1.71$)$ but not among seronegative cases. The results from lagged analyses, using BMI measures at 4 years and 6 years prior to RA diagnosis, were consistent with those of time-varying BMI and cumulative average BMI demonstrating a reduced likelihood for observed associations to be due to reverse causation. Also, we observed that being in the upper range of normal BMI $\left(23.0-24.9 \mathrm{~kg} / \mathrm{m}^{2}\right)$ and overweight at age 18 years was only associated with increased risk of seropositive RA, but not seronegative RA in pooled analysis (table 4). The sensitivity analysis with additional adjustment for women's reproductive factors (menarche age, parity/breastfeeding, menopausal status and postmenopausal hormone use), demonstrated no major change in point estimates or significance of the findings. The lagged analyses and analyses excluding cancer cases gave similar results. And lastly, in NHSII, sensitivity analyses replacing pregnancy weights with non-pregnant weights from the prior cycle, demonstrated no difference from the primary results.

\section{DISCUSSION}

In two large prospective cohort studies of women, we observed a significant association between being overweight and obese and developing seropositive and seronegative RA, that appeared to be stronger among women diagnosed at younger ages. We also observed that being overweight or obese at 18 years of age was associated with a 35\% increased risk of developing RA, and an almost 50\% increased risk of developing seropositive RA in adulthood. We observed a 'dose-effect' of obesity years on risk of RA at age 55 years or younger with a $37 \%$ increased risk of RA associated with a history of 10 years of being obese.

A recent large population-based case-control study, the Swedish Epidemiological Investigation of Rheumatoid Arthritis (EIRA) cohort observed a significant association between obesity and ACPA-negative RA among women (OR 1.6 (95\% CI 1.0 to 3.3)), and no association between obesity and ACPA-positive RA among women. ${ }^{17}$ Similarly, a Danish study of 515 RA cases observed a statistically significant association between obesity and risk of ACPA-negative RA (OR 1.34, (95\% CI 1.73 to 5.98)). ${ }^{13}$ Yet the population-based, prospective cohort EPIC-Norfolk study observed that after following participants for a median of 14 years, obesity was not significantly associated with increased risk of inflammatory arthritis or RA in their multivariable adjusted models. ${ }^{11}$ An earlier study using the NHS cohort with only 115 incident definite RA cases, observed a trend towards a positive association between increasing BMI and RA which was not statistically significant, ${ }^{35}$ likely due to being underpowered, and did not stratify by age at diagnosis of RA. The differences between our findings and those of prior studies may be explained by differences in population demographics and study design. Case-control studies obtain covariate information retrospectively, and thus are vulnerable to recall bias. Weight may change near RA diagnosis due to metabolic effects of preclinical RA and reduced activity levels due to musculoskeletal symptoms. Our study collected data on height and weight prospectively, before the diagnosis of RA. Prior studies also did not adjust for physical activity in their analyses, a potentially important confounder of the BMI and RA association. Our study excluded all women with psoriasis, previously demonstrated to be associated with obesity, to eliminate possible misclassification of psoriatic arthritis as seronegative RA. ${ }^{36}$ To ensure that our referent BMI category included predominantly healthy women, we excluded those with extreme low weight $\left(\mathrm{BMI}<18.5 \mathrm{~kg} / \mathrm{m}^{2}\right.$ ).

The prospective Iowa Women's Health cohort study identified 158 RA cases and observed no association between BMI $>29.2 \mathrm{~kg} / \mathrm{m}^{2}$ compared with a BMI $<23.4 \mathrm{~kg} / \mathrm{m}^{2}$ assessed at baseline and incident RA assessed 11 years later. They also did not observe an association between BMI at age 18 years and adult onset RA. ${ }^{16}$ Compared with the NHS and NHSII, the women enrolled in the Iowa Women's Health study were generally older at enrolment (mean age 61.5 years) with a mean age at symptom onset of 67.8 years (range 57-79 years). In our study, we observed that the association for BMI and RA was stronger among women diagnosed with RA at earlier ages, and we did not observe a significant association between BMI and RA when we restricted to RA cases diagnosed after age 55 years. Hence, if BMI is a weak risk factor for RA diagnosed at older ages, a cohort comprised primarily of older women would not observe this association. This could also account for the lack of association between BMI and 
Table 2 HRs for incident RA, and incident seropositive or seronegative RA phenotypes, according to time-varying Body Mass Index (BMI) in NHS and NHS II

\begin{tabular}{|c|c|c|c|c|c|c|c|c|}
\hline \multirow[b]{2}{*}{ BMI } & \multicolumn{3}{|c|}{ Nurses' Health Study } & \multicolumn{3}{|c|}{ Nurses' Health Study II } & \multirow[b]{2}{*}{ Pooled HR $(95 \% \mathrm{Cl})$} & \multirow[b]{2}{*}{ p Hett } \\
\hline & $\begin{array}{l}\text { Number of cases } \\
\text { /Person-years }\end{array}$ & $\begin{array}{l}\text { Age-adjusted } \\
\text { HR }(95 \% \mathrm{Cl})\end{array}$ & $\begin{array}{l}\text { Multivariable } \\
\text { HR }(95 \% \mathrm{Cl})^{*}\end{array}$ & $\begin{array}{l}\text { Number of cases/ } \\
\text { person-years }\end{array}$ & Age-adjusted HR (95\% Cl) & Multivariable HR $(95 \% \mathrm{Cl})^{*}$ & & \\
\hline \multicolumn{9}{|l|}{ All RA cases } \\
\hline \multicolumn{9}{|l|}{ All RA } \\
\hline $18.5-24.9$ & $407 / 1490667$ & 1.00 & 1.00 & $128 / 1040272$ & 1.00 & 1.00 & 1.00 & \\
\hline $25.0-29.9$ & 271/816 778 & 1.15 (0.98 to 1.34$)$ & $1.16(0.99$ to 1.35$)$ & 118/492801 & $1.76(1.37$ to 2.27$)$ & $1.68(1.30$ to 2.17$)$ & 1.37 (0.95 to 1.98$)$ & 0.015 \\
\hline$\geq 30.0$ & $148 / 457750$ & $1.11(0.92$ to 1.35$)$ & $1.12(0.92$ to 1.37$)$ & $109 / 401445$ & 1.92 (1.48 to 2.49$)$ & $1.72(1.31$ to 2.45$)$ & 1.37 (0.91 to 2.09$)$ & 0.012 \\
\hline$p$ trend & & 0.167 & 0.150 & & $<0.001$ & $<0.001$ & 0.068 & \\
\hline \multicolumn{9}{|c|}{ Seropositive RA } \\
\hline $18.5-24.9$ & $257 / 1390405$ & 1.00 & 1.00 & $84 / 1019688$ & 1.00 & 1.00 & 1.00 & \\
\hline $25.0-29.9$ & $166 / 756204$ & $1.15(0.94$ to 1.40$)$ & $1.15(0.94$ to 1.41$)$ & 74/481 569 & 1.69 (1.24 to 2.32$)$ & $1.63(1.19$ to 2.24$)$ & 1.34 (0.96 to 1.88$)$ & 0.071 \\
\hline$\geq 30.0$ & $87 / 421741$ & $1.09(0.85$ to 1.40$)$ & $1.08(0.84$ to 1.39$)$ & $74 / 390262$ & $1.98(1.44$ to 2.73$)$ & 1.81 (1.30 to 2.52$)$ & $1.38(0.83$ to 2.30$)$ & 0.015 \\
\hline$p$ trend & & 0.345 & 0.386 & & $<0.001$ & $<0.001$ & 0.133 & \\
\hline \multicolumn{9}{|c|}{ Seronegative RA } \\
\hline $18.5-24.9$ & 150/1 484299 & 1.00 & 1.00 & $44 / 1038235$ & 1.00 & 1.00 & 1.00 & \\
\hline $25.0-29.9$ & $105 / 813544$ & $1.18(0.91$ to 1.51$)$ & $1.19(0.92$ to 1.54$)$ & $44 / 491544$ & $1.92(1.26$ to 2.93$)$ & $1.80(1.18$ to 2.76$)$ & $1.41(0.95$ to 2.11$)$ & 0.102 \\
\hline$\geq 30.0$ & $61 / 456258$ & $1.21(0.89$ to 1.64$)$ & $1.25(0.91$ to 1.70$)$ & $35 / 400415$ & 1.84 (1.17 to 2.88$)$ & $1.58(0.99$ to 2.51$)$ & $1.34(1.03$ to 1.74$)$ & 0.406 \\
\hline$p$ trend & & 0.169 & 0.127 & & 0.007 & 0.053 & 0.017 & \\
\hline \multicolumn{9}{|c|}{$R A$ onset $\leq 55$ years of age } \\
\hline \multicolumn{9}{|l|}{ All RA } \\
\hline $18.5-24.9$ & 170/802 579 & 1.00 & 1.00 & 112/999 985 & 1.00 & 1.00 & 1.00 & \\
\hline $25.0-29.9$ & $86 / 317192$ & 1.21 (0.93 to 1.58$)$ & 1.22 (0.93 to 1.58$)$ & $101 / 460156$ & 1.82 (1.39 to 2.39$)$ & $1.72(1.31$ to 2.27$)$ & 1.45 (1.03 to 2.03$)$ & 0.072 \\
\hline$\geq 30.0$ & $56 / 166957$ & 1.51 (1.11 to 2.05$)$ & 1.51 (1.10 to 2.06$)$ & $93 / 370245$ & 2.03 (1.53 to 2.68 ) & 1.79 (1.34 to 2.39$)$ & 1.65 (1.34 to 2.05$)$ & 0.421 \\
\hline $\mathrm{p}$ trend & & 0.007 & 0.008 & & $<0.001$ & $<0.001$ & $<0.001$ & \\
\hline \multicolumn{9}{|c|}{ Seropositive RA } \\
\hline $18.5-24.9$ & 108/739670 & 1.00 & 1.00 & $72 / 979647$ & 1.00 & 1.00 & 1.00 & \\
\hline $25.0-29.9$ & $56 / 287336$ & $1.27(0.92$ to 1.76$)$ & 1.27 (0.91 to 1.76$)$ & $65 / 449113$ & 1.84 (1.31 to 2.57$)$ & 1.76 (1.25 to 2.47$)$ & 1.49 (1.08 2.04) & 0.178 \\
\hline$\geq 30.0$ & $36 / 149759$ & 1.57 (1.07 to 2.31$)$ & 1.56 (1.05 to 2.31$)$ & $61 / 359345$ & 2.07 (1.46 to 2.93 ) & 1.87 (1.31 to 2.68$)$ & $1.72(1.32$ to 2.24$)$ & 0.498 \\
\hline $\mathrm{p}$ trend & & 0.015 & 0.019 & & $<0.001$ & $<0.001$ & $<0.001$ & \\
\hline \multicolumn{9}{|c|}{ Seronegative RA } \\
\hline $18.5-24.9$ & $62 / 798202$ & 1.00 & 1.00 & 40/997976 & 1.00 & 1.00 & 1.00 & \\
\hline $25.0-29.9$ & $30 / 315436$ & $1.16(0.75$ to 1.80$)$ & 1.17 (0.75 to 1.82$)$ & $36 / 458922$ & 1.83 (1.16 to 2.88 ) & 1.71 (1.08 to 2.70$)$ & 1.41 (0.97 to 2.04$)$ & 0.243 \\
\hline$\geq 30.0$ & 20/166 094 & $1.51(0.91$ to 1.52$)$ & $1.53(0.90$ to 2.59$)$ & $32 / 369247$ & $1.99(1.24$ to 3.18$)$ & 1.69 (1.04 to 2.75$)$ & 1.61 (1.13 to 2.31$)$ & 0.782 \\
\hline $\mathrm{p}$ trend & & 0.115 & 0.113 & & 0.004 & 0.037 & 0.009 & \\
\hline
\end{tabular}

Bold typeface indicates significant results.

${ }^{*}$ Adjusted for age, community median income, smoking (pack-years), alcohol use $(<5.0,5.0-<15.0, \geq 15 \mathrm{~g} /$ day) and physical activity (0-3, 3-9, 9-18, 18-27, $\geq 27$ METs/week). Additional adjustment for women's reproductive factors (menarche age, parity/breastfeeding, menopausal status and postmenopausal hormone use) did not change the results.

tp Value for test of heterogeneity (het) between the 2 cohorts. Risk estimates were pooled by using a DerSimonian and Laird random-effects model.
MET, metabolic equivalent; RA, rheumatoid arthritis. 
Table 3 HRs for incident RA, and incident seropositive or seronegative RA phenotypes, according to cumulative average Body Mass Index (BMI) in Nurses' Health Study and Nurses' Health Study II

\begin{tabular}{|c|c|c|c|c|c|c|c|c|}
\hline \multirow[b]{2}{*}{ Cumulative average BMI } & \multicolumn{3}{|l|}{ Nurses' Health Study } & \multicolumn{3}{|c|}{ Nurses' Health Study II } & \multirow[b]{2}{*}{$\begin{array}{l}\text { Pooled HR } \\
(95 \% \mathrm{Cl})\end{array}$} & \multirow[b]{2}{*}{ p Het } \\
\hline & Number of cases/person-years & Age-adjusted HR (95\% Cl) & Multivariable HR $(95 \% \mathrm{Cl})^{*}$ & $\begin{array}{l}\text { Number of cases/ } \\
\text { person-years }\end{array}$ & $\begin{array}{l}\text { Age-adjusted HR } \\
(95 \% \mathrm{Cl})\end{array}$ & $\begin{array}{l}\text { Multivariable HR } \\
(95 \% \mathrm{CI})^{*}\end{array}$ & & \\
\hline \multicolumn{9}{|l|}{ All $R A$ cases } \\
\hline \multicolumn{9}{|l|}{ All RA } \\
\hline $8.5-24.9$ & $471 / 1708379$ & 1.00 & 1.00 & $168 / 1175594$ & 1.00 & 1.00 & 1.00 & \\
\hline $25.0-29.9$ & $247 / 741443$ & 1.15 (0.99 to 1.35$)$ & 1.17 (1.00 to 1.37$)$ & $103 / 454650$ & 1.47 (1.15 to 1.88$)$ & 1.38 (1.08 to 1.77$)$ & 1.23 (1.06 to 144$)$ & 0.271 \\
\hline$\geq 30.0$ & $108 / 315373$ & 1.18 (0.96 to 1.46$)$ & 1.21 (0.97 to 1.50$)$ & $84 / 304274$ & 1.73 (1.33 to 2.25$)$ & 1.53 (1.16 to 2.01$)$ & $1.34(1.06$ to 1.68$)$ & 0.183 \\
\hline $\mathrm{p}$ trend & & 0.052 & 0.034 & & $<0.001$ & 0.001 & $<0.001$ & \\
\hline \multicolumn{9}{|l|}{ Seropositive RA } \\
\hline $18.5-24.9$ & 289/1 596366 & 1.00 & 1.00 & $105 / 1152762$ & 1.00 & 1.00 & 1.00 & \\
\hline $25.0-29.9$ & 157/683973 & $1.24(1.02$ to 1.51$)$ & 1.25 (1.02 to 1.52$)$ & $69 / 443759$ & $1.59(1.17$ to 2.16$)$ & $1.52(1.11$ to 2.06$)$ & $1.32(1.11$ to 1.58$)$ & 0.296 \\
\hline$\geq 30.0$ & $64 / 288011$ & 1.20 (0.91 to 1.57$)$ & $1.21(0.92$ to 1.60$)$ & 58/294 997 & $1.92(1.39$ to 2.66$)$ & 1.75 (1.25 to 2.45$)$ & 1.44 (1.00 to 2.06$)$ & 0.100 \\
\hline $\mathrm{p}$ trend & & 0.062 & 0.058 & & $<0.001$ & $<0.001$ & 0.004 & \\
\hline \multicolumn{9}{|l|}{ Seronegative RA } \\
\hline $18.5-24.9$ & $182 / 1701227$ & 1.00 & 1.00 & $63 / 1173261$ & 1.00 & 1.00 & 1.00 & \\
\hline $25.0-29.9$ & $90 / 738623$ & 1.06 (0.82 to 1.37$)$ & 1.09 (0.84 to 1.41$)$ & $34 / 453555$ & $1.29(0.85$ to 1.96$)$ & $1.19(0.78$ to 1.81$)$ & 1.11 (0.89 to 1.39$)$ & 0.729 \\
\hline$\geq 30.0$ & $44 / 314252$ & 1.21 (0.87 to 1.69 ) & 1.25 (0.89 to 1.76$)$ & 26/303 378 & 1.43 (0.90 to 2.27 ) & 1.20 (0.75 to 1.93$)$ & 1.23 (0.94 to 1.63$)$ & 0.888 \\
\hline $\mathrm{p}$ trend & & 0.263 & 0.191 & & 0.104 & 0.411 & 0.125 & \\
\hline \multicolumn{9}{|l|}{$R A$ onset $\leq 55$ years of age } \\
\hline \multicolumn{9}{|l|}{ All RA } \\
\hline $18.5-24.9$ & 196/882 579 & 1.00 & 1.00 & $147 / 1125955$ & 1.00 & 1.00 & 1.00 & \\
\hline $25.0-29.9$ & $74 / 282849$ & 1.12 (0.86 to 1.47$)$ & 1.12 (0.86 to 1.47$)$ & $88 / 423641$ & 1.51 (1.16 to 1.97$)$ & 1.41 (1.08 to 1.84$)$ & $1.26(1.01 .1 .57)$ & 0.244 \\
\hline$\geq 30.0$ & $42 / 121301$ & 1.46 (1.04 to 2.04$)$ & 1.44 (1.02 to 2.03$)$ & $71 / 280790$ & 1.79 (1.34 to 2.38 ) & 1.56 (1.16 to 2.09$)$ & 1.51 (1.20 to 1.88$)$ & 0.727 \\
\hline $\mathrm{p}$ trend & & 0.031 & 0.039 & & $<0.001$ & 0.002 & $<0.001$ & \\
\hline \multicolumn{9}{|l|}{ Seropositive RA } \\
\hline $18.5-24.9$ & $126 / 814611$ & 1.00 & 1.00 & $92 / 1103419$ & 1.00 & 1.00 & 1.00 & \\
\hline $25.0-29.9$ & $47 / 254650$ & 1.15 (0.82 to 1.60$)$ & 1.13 (0.80 to 1.59$)$ & $58 / 412959$ & 1.61 (1.15 to 2.23$)$ & 1.52 (1.09 to 2.12 ) & 1.31 (0.98 to 1.75$)$ & 0.226 \\
\hline$\geq 30.0$ & 27/107 504 & $1.51(0.99$ to 2.29$)$ & $1.48(0.97 .2 .28)$ & $48 / 271727$ & 1.95 (1.37 to 2.78$)$ & 1.75 (1.22 to 2.52$)$ & 1.63 (1.24 to 2.16$)$ & 0.564 \\
\hline $\mathrm{p}$ trend & & 0.056 & 0.074 & & $<0.001$ & 0.002 & $<0.001$ & \\
\hline \multicolumn{9}{|l|}{ Seronegative RA } \\
\hline $18.5-24.9$ & 70/877 769 & 1.00 & 1.00 & $55 / 1123656$ & 1.00 & 1.00 & 1.00 & \\
\hline $25.0-29.9$ & $27 / 281358$ & 1.14 (0.73 to 1.78$)$ & 1.16 (0.73 to 1.82$)$ & $30 / 422569$ & 1.37 (0.87 to 2.14 ) & 1.26 (0.80 to 1.98$)$ & 1.21 (0.88 to 1.66 ) & 0.793 \\
\hline$\geq 30.0$ & $15 / 120604$ & $1.48(0.84$ to 2.59$)$ & 1.48 (0.83 to 2.63$)$ & $23 / 279920$ & 1.54 (0.95 to 2.52$)$ & 1.28 (0.77 to 2.12$)$ & 1.36 (0.93 to 1.99$)$ & 0.709 \\
\hline$p$ trend & & 0.173 & 0.174 & & 0.065 & 0.299 & 0.100 & \\
\hline
\end{tabular}

Bold typeface indicates significant results.

*Adjusted for age, community median income, smoking (pack-years), alcohol use $(<5.0,5.0-<15.0, \geq 15 \mathrm{~g} /$ day) and physical activity (0-3, 3-9, 9-18, 18-27, $\geq 27$ METs/week).

tp Value for test of heterogeneity (het) between the 2 cohorts. Risk estimates were pooled by using a DerSimonian and Laird random-effects model.

MET, metabolic equivalent; RA, rheumatoid arthritis. 


\begin{tabular}{|c|c|c|c|c|c|c|c|c|}
\hline \multirow[b]{2}{*}{ BMI at age 18} & \multicolumn{3}{|c|}{ Nurses' Health Study } & \multicolumn{3}{|c|}{ Nurses' Health Study II } & \multirow[b]{2}{*}{ Pooled HR $(95 \% \mathrm{Cl})$} & \multirow[b]{2}{*}{ p Het +} \\
\hline & $\begin{array}{l}\text { Number of cases/ } \\
\text { person-years }\end{array}$ & $\begin{array}{l}\text { Age-adjusted } \\
\text { HR }(95 \% \mathrm{Cl})\end{array}$ & $\begin{array}{l}\text { Multivariable } \\
\text { HR }(95 \% \mathrm{Cl})^{*}\end{array}$ & $\begin{array}{l}\text { Number of cases/ } \\
\text { person-years }\end{array}$ & $\begin{array}{l}\text { Age-adjusted } \\
\text { HR }(95 \% \mathrm{Cl})\end{array}$ & $\begin{array}{l}\text { Multivariable } \\
\text { HR }(95 \% \mathrm{Cl})^{*}\end{array}$ & & \\
\hline \multicolumn{9}{|l|}{ All RA cases } \\
\hline \multicolumn{9}{|l|}{ All RA } \\
\hline $18.5-20.0$ & 245/813 471 & 1.00 & 1.00 & $111 / 740798$ & 1.00 & 1.00 & 1.00 & \\
\hline $20.0-22.9$ & $307 / 1065987$ & 0.96 (0.81 to 1.13$)$ & 0.95 (0.80 to 1.12 ) & $153 / 780354$ & 1.30 (1.02 to 1.66$)$ & 1.27 (0.99 to 1.62$)$ & 1.08 (0.81 to 1.43$)$ & 0.056 \\
\hline $23.0-24.9$ & $107 / 286070$ & 1.23 (0.98 to 1.54$)$ & 1.18 (0.93 to 1.48$)$ & $36 / 200835$ & $1.20(0.82$ to 1.74$)$ & 1.10 (0.76 to 1.61$)$ & 1.16 (0.95 to 1.40$)$ & 0.780 \\
\hline$\geq 25.0$ & 93/225 192 & 1.36 (1.07 to 1.73$)$ & $1.26(0.99$ to 1.61$)$ & 53/197317 & 1.78 (1.28 to 2.46$)$ & $1.53(1.10$ to 2.14$)$ & 1.35 (1.11 to 1.64$)$ & 0.355 \\
\hline$p$ trend & & 0.004 & 0.029 & & 0.001 & 0.024 & 0.002 & \\
\hline \multicolumn{9}{|l|}{ Seropositive RA } \\
\hline $18.5-20.0$ & $145 / 755465$ & 1.00 & 1.00 & 68/725 995 & 1.00 & 1.00 & 1.00 & \\
\hline $20.0-22.9$ & 185/992 789 & 0.97 (0.78 to 1.21$)$ & 0.96 (0.77 to 1.19$)$ & $99 / 763654$ & 1.39 (1.02 to 1.89$)$ & 1.35 (0.99 to 1.83$)$ & 1.11 (0.80 to 1.55$)$ & 0.080 \\
\hline $23.0-24.9$ & $73 / 265486$ & $1.42(1.07$ to 1.88$)$ & 1.34 (1.01 to 1.78$)$ & $27 / 195732$ & 1.49 (0.95 to 2.33$)$ & 1.36 (0.87 to 2.13$)$ & 1.35 (1.06 to 1.71$)$ & 0.957 \\
\hline$\geq 25.0$ & $57 / 206859$ & 1.42 (1.05 to 1.94$)$ & $1.30(0.95$ to 1.77$)$ & 38/191338 & 2.10 (1.41 to 3.13$)$ & 1.81 (1.21 to 2.70$)$ & 1.49 (1.08 to 2.06$)$ & 0.201 \\
\hline $\mathrm{p}$ trend & & 0.004 & 0.025 & & $<0.001$ & 0.005 & $<0.001$ & \\
\hline \multicolumn{9}{|l|}{ Seronegative RA } \\
\hline $18.5-20.0$ & 100/810 187 & 1.00 & 1.00 & 43/739 391 & 1.00 & 1.00 & 1.00 & \\
\hline $20.0-22.9$ & $122 / 1061975$ & 0.93 (0.72 to 1.22 ) & 0.93 (0.71 to 1.21 ) & $54 / 778574$ & 1.17 (0.78 to 1.75$)$ & 1.15 (0.77 to 1.71$)$ & 0.99 (0.79 to 1.23$)$ & 0.387 \\
\hline $23.0-24.9$ & $34 / 284604$ & 0.96 (0.65 to 1.41$)$ & 0.93 (0.63 to 1.37 ) & $9 / 200346$ & $0.76(0.37$ to 1.56$)$ & 0.71 (0.34 to 1.45$)$ & $0.87(0.62$ to 1.23$)$ & 0.519 \\
\hline$\geq 25.0$ & $36 / 223960$ & 1.29 (0.88 to 1.89$)$ & 1.22 (0.83 to 1.79$)$ & 15/196 709 & $1.28(0.71$ to 2.31$)$ & 1.12 (0.62 to 2.02 ) & 1.19 (0.86 to 1.64$)$ & 0.810 \\
\hline $\mathrm{p}$ trend & & 0.310 & 0.478 & & 0.654 & 0.980 & 0.570 & \\
\hline \multicolumn{9}{|c|}{$R A$ onset $\leq 55$ years of age } \\
\hline \multicolumn{9}{|l|}{ All RA } \\
\hline $18.5-20.0$ & $84 / 375856$ & 1.00 & 1.00 & $95 / 700885$ & 1.00 & 1.00 & 1.00 & \\
\hline $20.0-22.9$ & $123 / 497886$ & 1.12 (0.85 to 1.48$)$ & $1.11(0.84$ to 1.46$)$ & $131 / 737890$ & $1.30(1.00$ to 1.70$)$ & 1.27 (0.98 to 1.66$)$ & 1.19 (0.98 to 1.44$)$ & 0.481 \\
\hline $23.0-24.9$ & $39 / 131270$ & 1.31 (0.89 to 1.92$)$ & 1.26 (0.86 to 1.85$)$ & 29/190 217 & 1.12 (0.74 to 1.70$)$ & 1.04 (0.69 to 1.58$)$ & 1.16 (0.87 to 1.54 ) & 0.507 \\
\hline$\geq 25.0$ & $44 / 108004$ & 1.82 (1.26 to 2.62$)$ & 1.70 (1.18 to 2.47$)$ & $49 / 187052$ & 1.91 (1.35 to 2.69$)$ & 1.66 (1.17 to 2.36$)$ & $1.68(1.30$ to 2.17$)$ & 0.924 \\
\hline $\mathrm{p}$ trend & & 0.001 & 0.005 & & $<0.001$ & 0.011 & $<0.001$ & \\
\hline \multicolumn{9}{|l|}{ Seropositive RA } \\
\hline $18.5-20.0$ & $52 / 343779$ & 1.00 & 1.00 & $56 / 686316$ & 1.00 & 1.00 & 1.00 & \\
\hline $20.0-22.9$ & $74 / 457265$ & 1.06 (0.74 to 1.52$)$ & 1.05 (0.73 to 1.49$)$ & $84 / 721457$ & $1.43(1.02$ to 2.00$)$ & $1.39(0.99$ to 1.94$)$ & 1.21 (0.92 to 1.60$)$ & 0.262 \\
\hline $23.0-24.9$ & 28/119954 & 1.51 (0.95 to2.40) & 1.45 (0.91 to 2.30$)$ & $24 / 185247$ & 1.60 (0.99 to 2.59 ) & 1.49 (0.92 to 2.41$)$ & 1.47 (1.05 to 2.05$)$ & 0.933 \\
\hline$\geq 25.0$ & 28/96989 & $1.90(1.20$ to 3.02$)$ & 1.74 (1.09 to 2.78$)$ & $34 / 181147$ & 2.28 (1.49 to 3.50$)$ & $1.99(1.29$ to 3.06$)$ & 1.87 (1.36 to 2.56$)$ & 0.686 \\
\hline $\mathrm{p}$ trend & & 0.003 & 0.010 & & $<0.001$ & 0.002 & $<0.001$ & \\
\hline \multicolumn{9}{|l|}{ Seronegative RA } \\
\hline $18.5-20.0$ & $32 / 373858$ & 1.00 & 1.00 & 39/699 511 & 1.00 & 1.00 & 1.00 & \\
\hline $20.0-22.9$ & $49 / 495352$ & 1.19 (0.76 to 1.86$)$ & $1.19(0.76$ to 1.86$)$ & $47 / 736139$ & 1.13 (0.74 to 1.72$)$ & $1.11(0.72$ to 1.70$)$ & 1.15 (0.84 to 1.56$)$ & 0.817 \\
\hline $23.0-24.9$ & $11 / 130352$ & 0.98 (0.49 to 1.94$)$ & 0.95 (0.48 to 1.89 ) & $5 / 189733$ & 0.46 (0.18 to 1.17$)$ & 0.43 (0.17 to 1.10$)$ & $0.68(0.32$ to 1.46$)$ & 0.184 \\
\hline$\geq 25.0$ & $16 / 107182$ & 1.71 (0.94 to 3.12$)$ & $1.64(0.89$ to 3.01$)$ & $15 / 186461$ & $1.40(0.77$ to 2.54$)$ & $1.22(0.67$ to 2.24$)$ & 1.41 (0.92 to 2.17 ) & 0.506 \\
\hline$p$ trend & & 0.150 & 0.203 & & 0.599 & 0.918 & 0.361 & \\
\hline
\end{tabular}

Bold typeface indicates significant results.

*Adjusted for age, community median income, smoking (pack-years), alcohol use ( $<5.0,5.0-<15.0, \geq 15 \mathrm{~g} /$ day) and physical activity (0-3, 3-9, 9-18, 18-27, $\geq 27$ METs/week).

tp Value for test of heterogeneity (het) between the 2 cohorts. Risk estimates were pooled by using a DerSimonian and Laird random-effects model.

MET, metabolic equivalent; RA, rheumatoid arthritis.

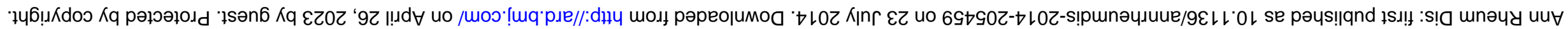


risk of RA in the UK primary care study that included 579 RA cases spanning a wide age range of $20-79$ years, ${ }^{14}$ and for the lack of association observed in the prior NHS study. ${ }^{35}$

Our study findings are consistent with those of prior studies that identified an association between obesity and RA diagnosis among younger women. A population-based case control study of RA including 349 incident RA cases and 1457 controls observed that premenopausal women in the highest quartile of BMI had a RR of 1.5 (95\% CI 1.0 to 2.3), and postmenopausal women had a RR of 1.4 (95\% CI 1.0 to 2.0) for developing RA. ${ }^{8}$ A case-control study of Minnesota residents composed of 813 RA cases and 813 controls observed a similar phenomenon where a history of obesity was associated with RA diagnosis under 60 years of age (OR 1.32, 95\% CI 1.00 to 1.72), but not associated with RA diagnosed at age 60 years or more (OR $1.15,95 \%$ CI 0.82 to 1.61$).{ }^{10}$ With recent understanding of the metabolic activity of adipose tissue, there is a growing recognition of obesity as a proinflammatory state. ${ }^{3}$ There is evidence suggesting a role of obesity in the development of other chronic diseases, such as type 2 diabetes and cardiovascular disease. ${ }^{5}$ It is hypothesised that adipose tissue may be exerting its effects on the pathogenesis of these diseases via inflammatory adipokines. ${ }^{3}$ The systemic overload of adipose-derived cytokines is a proposed cause of immune, endocrine, reproductive and metabolic dysfunction in obesity. Studies have shown increased levels of proinflammatory adipokines in obese and overweight persons diagnosed with metabolic syndrome or cardiovascular disease. ${ }^{37}$

Adipokines originate in adipose tissue and are secreted by adipocytes and adipose-resident macrophages. Adipocytes present in obese and overweight individuals have been shown to secrete inflammatory markers such as CRP, amyloid A, TNF- $\alpha$, IL-6, interleukin-1 $\beta$ (IL-1 $\beta$ ), monocyte chemotactic protein-1 (MCP-1), and macrophage migration inhibitory factor (MIF). ${ }^{4}{ }^{5} 3$ Studies have shown significantly elevated levels of these inflammatory markers in preclinical RA. ${ }^{38-41}$ Hence, there is biological plausibility to implicate obesity in RA pathogenesis. The tests for interactions between BMI and other known risk factors for RA were not significant. While physical activity and BMI are highly correlated variables, adding physical activity, as we have done, does not attenuate the risk associated with BMI. Other cohorts, such as that in Rochester, Minnesota, have observed a gradual increase in the population-based incidence of RA over time, especially among women, and have attributed this to rising rates of obesity. ${ }^{10}$ By contrast, the NHS and NHS2 are select birth cohorts, and thus it is not possible to obtain population-based incidence rates. Future studies examining the joint influence of BMI, physical activity and smoking on RA risk would add knowledge to the mechanisms leading to RA.

Our study has a number of strengths. We prospectively identified incident cases of RA from two large cohort studies, which enabled the detailed collection of predisease measures of BMI as early as 18 years of age, and information on potential confounders such as smoking status, alcohol use and physical activity allowed for time-varying analyses. Lagged analyses using single BMI measures at 4 years and 6 years prior to RA diagnosis yielded results consistent with our time-varying BMI and cumulative average BMI results indicating that our findings are unlikely to be influenced by recall bias, preclinical metabolic changes, or reverse causation. Our cumulative BMI results suggest that long-term obesity and overweight exposures are strongly associated with risk of RA. Also, by using two cohorts, we were able to examine associations between BMI and RA diagnosed at different ages.
We acknowledge the limitations of our study. BMI is recognised as a valid measure of absolute fat mass adjusted for height, yet the use of BMI as a measure of fat mass decreases over the life-course. ${ }^{42}$ Among middle-aged adults, the vast majority of variation in weight, after accounting for height, is attributed to differences in fat. However, many elderly people lose substantial amounts of lean body mass in their older age which contributes to interindividual difference observed between older adults. ${ }^{43}$ For these reasons, the lack of an observed association between BMI and RA diagnosed at older ages may result from limitations of BMI as an accurate measure of fat mass among older women. Our definition of early RA onset of 55 years or younger was selected based on prior studies that have used a range of thresholds to distinguish early from late onset RA. ${ }^{32}$ We also considered that women, on average, reach their peak BMI between the ages of 50 and $59 .{ }^{33}$ Hence, our findings require replication in an independent cohort. Our findings also raise the possibility that our observed BMI and RA association may be due to an unhealthy diet rather than BMI alone. Further studies are needed to investigate whether dietary factors are more related to risk of RA. We acknowledge that our study was limited to women, and may not be generalisable to men with RA. Lastly, there is potential misclassification in separating those who are seropositive from those who are seronegative. Since ACPA was available only in later years of the cohorts, it is possible that some subjects who were RF-negative may be ACPA-positive, but since these biomarkers tend to be highly correlated, we expect that the misclassification of RA cases is minimal.

The incidence of RA in our population is in keeping with prior reports from European countries, yet is lower than prior estimates from the Olmsted County, Minnesota's hospital case-based reports. ${ }^{44}$ This is likely due to the fact that we conducted a cohort analysis among a population of healthy, working women who were enrolled in NHS from ages 30 to 55 years, studied over only 25 years, rather than reporting a lifetime risk or incidence rate over the lifespan. Hence, our ability to capture subjects with early symptoms, or who were not working as nurses at baseline was limited and the generalisability of our findings was also limited to this middle-age range. However, our ability to observe an association between BMI and RA risk while applying our stringent case definitions supports the robust nature of this association.

\section{CONCLUSIONS}

In conclusion, we observed that being obese increased the risk of RA in women by $40-70 \%$ depending on age and serologic status. The highest risk for RA was among women who were overweight or obese at age 18 years, emphasising the public health importance of combating the obesity epidemic at all ages. Our study implicates being overweight or obese throughout adult life as a risk factor in the development of seropositive and seronegative RA for women diagnosed with RA at age 55 years or younger. The attenuated association between BMI and RA diagnosed at older ages may reflect differences in the pathophysiology of RA diagnosed at earlier ages compared with that diagnosed at older ages, or may be a result of the limitations of $\mathrm{BMI}$ as a measure of total fat mass as women age.

Correction notice This article has been corrected since it was published Online First. The authors who co-led the study have been included on the first page.

Acknowledgements We thank the participants in NHS and NHS II cohorts for their dedication and continued participation in these longitudinal studies, as well as NHS staff in the Channing Division of Network Medicine, Department of Medicine, Brigham and Women's Hospital and Harvard Medical School for their assistance with this project. 
Contributors BL had full access to all the data in the study and takes responsibility for the integrity of the data and the accuracy of the data analysis. All authors have made substantial contributions to the conception and design of the study, or data analysis and interpretation of data, drafting the article and final approval.

Funding The work reported herein was supported by National Institutes of Health (grants AR061362, AR049880, AR052403, AR047782, AR059073, CA87969, CA50385, CA176726).

Competing interests $\mathrm{LH}$ was supported by a Canadian Institute of Health Research (CIHR) Fellowship Award.

Ethics approval Partners Health Care, Inc.

Provenance and peer review Not commissioned; externally peer reviewed.

\section{REFERENCES}

1 Barry CL, Gollust SE, Niederdeppe J. Are Americans ready to solve the weight of the nation? N Engl J Med 2012;367:389-91.

2 Clinical guidelines on the identification, evaluation, and treatment of overweight and obesity in adults-the evidence report. National Institutes of Health. Obes Res 1998;6(Suppl 2):51S-209S.

3 Gualillo 0, Gonzalez-Juanatey JR, Lago F. The emerging role of adipokines as mediators of cardiovascular function: physiologic and clinical perspectives. Trends Cardiovasc Med 2007:17:275-83.

4 Trayhurn P, Wood IS. Signalling role of adipose tissue: adipokines and inflammation in obesity. Biochem Soc Trans 2005;33(Pt 5):1078-81.

5 Panagiotakos DB, Pitsavos C, Yannakoulia M, et al. The implication of obesity and central fat on markers of chronic inflammation: the ATTICA study. Atherosclerosis 2005;183:308-15.

6 Mazurek T, Zhang L, Zalewski A, et al. Human epicardial adipose tissue is a source of inflammatory mediators. Circulation 2003;108:2460-6.

7 Fried SK, Bunkin DA, Greenberg AS. Omental and subcutaneous adipose tissues of obese subjects release interleukin-6: depot difference and regulation by glucocorticoid. J Clin Endocrinol Metab 1998;83:847-50.

8 Voigt LF, Koepsell TD, Nelson JL, et al. Smoking, obesity, alcohol consumption, and the risk of rheumatoid arthritis. Epidemiology 1994;5:525-32.

9 Symmons DP, Bankhead CR, Harrison BJ, et al. Blood transfusion, smoking, and obesity as risk factors for the development of rheumatoid arthritis: results from a primary care-based incident case-control study in Norfolk, England. Arthritis Rheum 1997:40:1955-61.

10 Crowson CS, Matteson EL, Davis JM III, et al. Contribution of obesity to the rise in incidence of rheumatoid arthritis. Arthritis Care Res (Hoboken) 2013:65:71-7.

11 Lahiri M, Luben RN, Morgan C, et al. Using lifestyle factors to identify individuals at higher risk of inflammatory polyarthritis (results from the European Prospective Investigation of Cancer-Norfolk and the Norfolk Arthritis Register-the EPIC-2-NOAR Study). Ann Rheum Dis 2014;73:219-26.

12 de Hair MJ, Landewe RB, van de Sande MG, et al. Smoking and overweight determine the likelihood of developing rheumatoid arthritis. Ann Rheum Dis 2012;72:1654-8.

13 Pedersen $\mathrm{M}$, Jacobsen $\mathrm{S}$, Klarlund $\mathrm{M}$, et al. Environmental risk factors differ between rheumatoid arthritis with and without auto-antibodies against cyclic citrullinated peptides. Arthritis Res Ther 2006;8:R133.

14 Rodriguez LA, Tolosa LB, Ruigomez A, et al. Rheumatoid arthritis in UK primary care: incidence and prior morbidity. Scand I Rheumatol 2009;38:173-7.

15 Uhlig T, Hagen KB, Kvien TK. Current tobacco smoking, formal education, and the risk of rheumatoid arthritis. J Rheumatol 1999:26:47-54.

16 Cerhan JR, Saag KG, Criswell LA, et al. Blood transfusion, alcohol use, and anthropometric risk factors for rheumatoid arthritis in older women. J Rheumatol 2002;29:246-54

17 Wesley A, Bengtsson C, Elkan AC, et al. Association between body mass index and anti-citrullinated protein antibody-positive and anti-citrullinated protein antibody-negative rheumatoid arthritis: results from a population-based case-control study. Arthritis Care Res (Hoboken) 2013;65:107-12.

18 Rich-Edwards JW, Corsano KA, Stampfer MJ. Test of the national death index and equifax nationwide death search. Am J Epidemiol 1994:140:1016-19.

19 Karlson EW, Sanchez-Guerrero J, Wright EA, et al. A connective tissue disease screening questionnaire for population studies. Ann Epidemiol 1995:5:297-302.
20 Arnett FC, Edworthy SM, Bloch DA, et al. The American Rheumatism Association 1987 revised criteria for the classification of rheumatoid arthritis. Arthritis Rheum 1988:31:315-24.

21 Rimm EB, Stampfer MJ, Colditz GA, et al. Validity of self-reported waist and hip circumferences in men and women. Epidemiology 1990;1:466-73.

22 Flint $\mathrm{AJ}$, Rexrode $\mathrm{KM}, \mathrm{Hu} \mathrm{FB}$, et al. Body mass index, waist circumference, and risk of coronary heart disease: a prospective study among men and women. Obes Res Clin Pract 2010;4:e171-81.

23 Abdullah A, Wolfe R, Stoelwinder JU, et al. The number of years lived with obesity and the risk of all-cause and cause-specific mortality. Int I Epidemiol 2011:40:985-96

24 Costenbader $\mathrm{KH}$, Feskanich D, Mandl LA, et al. Smoking intensity, duration, and cessation, and the risk of rheumatoid arthritis in women. Am J Med 2006;119:503 e501-509.

25 Karlson EW, Mandl LA, Hankinson SE, et al. Do breast-feeding and other reproductive factors influence future risk of rheumatoid arthritis? Results from the Nurses' Health Study. Arthritis Rheum 2004;50:3458-67.

26 Lahiri M, Morgan C, Symmons DP, et al. Modifiable risk factors for RA: prevention, better than cure? Rheumatology (Oxford) 2012;51:499-512.

27 Lu B, Solomon DH, Costenbader KH, et al. Alcohol consumption and risk of incident rheumatoid arthritis in women: A prospective study. Arthritis Rheum 2014. doi:10.1002/art.38634 [epub ahead of print 17 Apr 2014]

28 Stampfer MJ, Kang JH, Chen J, et al. Effects of moderate alcohol consumption on cognitive function in women. N Engl J Med 2005;352:245-53.

29 Ainsworth BE, Haskell WL, Leon AS, et al. Compendium of physical activities: classification of energy costs of human physical activities. Med Sci Sports Exerc 1993:25:71-80.

30 Arkema EV, Karlson EW, Costenbader $\mathrm{KH}$. A prospective study of periodontal disease and risk of rheumatoid arthritis. J Rheumatol 2010;37:1800-4.

31 DerSimonian R, Laird N. Meta-analysis in clinical trials. Control Clin Trials 1986;7:177-88

32 Camacho EM, Verstappen SM, Lunt $\mathrm{M}$, et al. Influence of age and sex on functional outcome over time in a cohort of patients with recent-onset inflammatory polyarthritis: results from the Norfolk Arthritis Register. Arthritis Care Res (Hoboken) 2011;63:1745-52.

33 Chumlea WC, Guo SS, Kuczmarski RJ, et al. Body composition estimates from NHANES III bioelectrical impedance data. Int I Obes Relat Metab Disord 2002:26:1596-609.

34 Alamanos Y, Voulgari PV, Drosos AA. Incidence and prevalence of rheumatoid arthritis, based on the 1987 American College of Rheumatology criteria: a systematic review. Semin Arthritis Rheum 2006:36:182-8.

35 Hernandez Avila M, Liang MH, Willett WC, et al. Reproductive factors, smoking, and the risk for rheumatoid arthritis. Epidemiology 1990;1:285-91.

36 Sterry W, Strober BE, Menter A. Obesity in psoriasis: the metabolic, clinical and therapeutic implications. Report of an interdisciplinary conference and review. $\mathrm{Br} J$ Dermatol 2007;157:649-55.

37 Shoelson SE, Herrero L, Naaz A. Obesity, inflammation, and insulin resistance. Gastroenterology 2007;132:2169-80.

38 Nielen MM, van Schaardenburg D, Reesink HW, et al. Increased levels of C-reactive protein in serum from blood donors before the onset of rheumatoid arthritis. Arthritis Rheum 2004;50:2423-7.

39 Deane $\mathrm{KD}, \mathrm{O}^{\prime}$ Donnell $\mathrm{Cl}$, Hueber $\mathrm{W}$, et al. The number of elevated cytokines and chemokines in preclinical seropositive rheumatoid arthritis predicts time to diagnosis in an age-dependent manner. Arthritis Rheum 2010;62:3161-72.

40 Kokkonen H, Soderstrom I, Rocklov J, et al. Up-regulation of cytokines and chemokines predates the onset of rheumatoid arthritis. Arthritis Rheum 2010;62:383-91.

41 Karlson EW, Chibnik LB, Tworoger SS, et al. Biomarkers of inflammation and development of rheumatoid arthritis in women from two prospective cohort studies. Arthritis Rheum 2009;60:641-52.

42 Spiegelman D, Israel RG, Bouchard C, et al. Absolute fat mass, percent body fat, and body-fat distribution: which is the real determinant of blood pressure and serum glucose? Am J Clin Nutr 1992;55:1033-44.

43 Gallagher D, Visser M, Sepulveda D, et al. How useful is body mass index for comparison of body fatness across age, sex, and ethnic groups? Am J Epidemiol 1996:143:228-39.

44 Myasoedova E, Crowson CS, Kremers HM, et al. Is the incidence of rheumatoid arthritis rising?: results from Olmsted County, Minnesota, 1955-2007. Arthritis Rheum 2010;62:1576-82. 